\title{
REGARDING THE ACCOUNTING POLICY AND TREATMENT PRESCRIBED BY THE IASB FOR THE EVALUATION AND EXPLORING ACTIVES
}

\author{
Professor Ph.D. Neamtu Horia - Academy of Economic Studies, Bucharest \\ Assistant Ph.D. Student Teiusan Sorin-Ciprian - „1 Decembrie 1918” University, Alba-Iulia
}

The International Accounting Standards Board considered the elaboration of a norm regarding the extraction industries, so as to standardize worldwide the accounting practices from this sector, a productive activity which became applicable (in the year of 2004) by the outcome of IFRS 6 "Exploration for and Evaluation of Mineral Resources". Through the present paper, we focused on this international financial reporting standard, underlining the accounting treatment and policy, established by the international organism of accounting standardizing (IASB) for the evaluation and exploration actives from the extraction industries (mining, oil and natural gas extraction).

\section{Referring to the specialized activities standards}

The international accounting standards "were not the result of an imagination exercise, but had been developed together with the practices that were generated in order to solve the special cases and particular economical processes, using international experience" ${ }^{1}$. One of the main objectives of the International Accounting Standards Board ${ }^{2}$ (IASB) is the development of the international accounting standards, now of the international financial reporting standards which are relevant for financial circumstances having a general purpose, belonging to all entities. But meanwhile the most part of IASs and IFRSs are being applied to entities from all activity areas, some of those deal with issues that appear in specific activity areas. As specialized activities, upon which the international organism of accountancy settling (IASB and before this, IASC) has focused for study, debating projects and eventually issuing international accounting standards or international financial reporting standards, the following can be observed: banks and other similar financial institutions (IAS 30 "Information presented in the banks and similar financial institutions financial situations"), agriculture (IAS 41 "Agriculture"), extraction industries (IFRS 6 "Exploration and evaluation of mineral resources"), the accountancy of assuring contracts (IFRS 4 "Assuring contracts"), the accountancy and reporting of the pension schemes (IAS 26 "The accounting and reporting of the pension schemes").

\section{IFRS 6 prior to receiving the statute of international financial reporting standard}

In July 2001, the IASB Council announced that the project for the extraction area would be started when time was at hand, admitting the importance of accounting the extraction activities in a general way, yet deciding in September 2002 that they were not reliable, finishing the detailed analysis needed for this project, obtaining the necessary information from the members and the development of the process in due time for implementing the changes before 2005, the year when

\footnotetext{
1 Adriana Dutescu, Guide for understanding and applying the International Accounting Standards, CECCAR Publishing House, Bucharest, 2001, page 14.

${ }^{2}$ Before this, the Committee for International Accounting Standards (IASC).
} 
many entities adopt IFRSs. ${ }^{3}$

On the $15^{\text {th }}$ of January 2004, IASB published the exposure project ED 6 "Exploration for and evaluation of mineral resources", asking for comments ${ }^{4}$ upon any aspect regarding the IFRS proposal with the same title. The project regarding the extraction industries accounting has been added in the IASB official work schedule in April 2003, establishing the objective of elaborating a temporary guide that permits, on one hand the clarifying of the means of application for IFRS standards to evaluation and prospecting activities and, on the other hand, the exemption for those enterprises having extraction activities from a certain number of disposals of these standards and from the IASB Area.

The reasons which led to this project's elaboration by IFRS are the following ${ }^{5}$ : [1] the evaluation and exploration of mineral resources are being excluded from other IFRS area of applicability (IAS 16 "Body standstill" and IAS 38 "Non-body actives"), and International Accounting Standards Committee is preoccupied by the fact that the accounting practices for these kinds of activities are different amongst the extraction industry sectors; and [2] an "on time" project on accounting and financial reporting for the extraction industry is not reliable for many entities that will like or will be asked to adopt IFRSs in 2005. On this account, the Council would like to provide guidance regarding the evaluation and exploration of expenses treatment, a fact that will increase the level of comparison between entities while avoiding un-useful debates on applying treatments, until completing the considerations referring to the mentioned accountancy issue.

The ED 6 project was elaborated so as to apply till the development of a more complete standard for the extraction industries sector. But it wasn't long until December, same year 2004, when IFRS 6 made its appearance "Exploration for and evaluation of mineral resources".

\section{The International Financial Reporting Standard "Exploration for and evaluation of mineral resources" - the sixth IFRS "produced" at IASB}

By the end of 2004 (on the $9^{\text {th }}$ of December), the international accounting organism of normalization (IASB) issued the sixth IFRS $^{6}$ from a total of eight existing in present time. The socalled Exploration for and evaluation of mineral resources, IFRS 6 is one of the most recent international standards of financial reporting "produced" or, how a specialty paperwork ${ }^{7}$ says, a new-come at the international financial reporting standards table. By publishing this IFRS, IASB offers for the first time, a guide regarding the accounting of the mineral resources exploration and evaluation expenses, including the recognition of the evaluation and exploration actives, completing the first stage of the IASB project, in order to accomplish at a world level the combining of some accounting practices for extraction activities.

The decision adopted by the IASB Council of elaborating an international financial reporting standard which deals with the exploration and evaluation of mineral resources is sustained by $^{8}$ : [a] the lack of an IFRS that especially refers to the accounting of these activities; [b] different opinions regarding the exploration and evaluation expenses accounting means, as according to IFRS;

\footnotetext{
3 International Accounting Standards Board, International Financial Reporting Standards including International Accounting Standards and their Interpretations on the $1^{\text {st }}$ of January 2006, CECCAR Publishing House, Bucharest, 2006, IFRS 6, IN3, page 612.

4 The deadline for the written comments on the project was the $16^{\text {th }}$ of April 2004. The IASB Council received 55 comments letters.

${ }^{5}$ The website www.iasplus.com

${ }^{6}$ The international financial reporting standard 6 "Exploration for and evaluation of mineral resources" was approved by 10 of the 14 members of the International Accounting Standards Board (IASB).

${ }^{7}$ Liliana Malciu, Niculae Feleaga, Reform after reform: the accounting from Romania in front of a new challenge, vol. I, Essays and the standards analysis IAS-IFRS, Economica Publishing House, Bucharest, 2005, page 193.

${ }^{8}$ The International Accounting Standards Committee, cit. op., International Financial Reporting Standard 6: Reasons for IFRS, IN1, page 612.
} 
[c] the fact that the accounting practices regarding the exploration and evaluation of the actives, imposed by other normalization organisms' demands are variable and often differ from the expenses practices from other sectors that can be seen as analogues; [d] the importance of exploration and evaluation expenses for entities involved in extraction activities; [e] the aspect of a great number of entities which have exploration and evaluation expenses make their financial situations in accordance with IFRSs and they are expecting to do this starting with 2005.

Although no IFRS has never treated the extraction activities directly so far, all IFRSs (including international accounting standards and the interpretations) are applied to those entities involved in the exploration and evaluation of mineral resources.

By the development of the financial reporting standard 6, a third IFRS addressed to new areas and topics in accountancy, IASB has fulfilled the need for a global accounting of extraction activities (mining, oil extraction, natural gas extraction), admitting that achieving a global agreement funded on a rigorous approach will demand the consulting extension. Considering those aspects, the IFRS 6 standard only completes the primary stage of the project IASB addressed to extraction activities. The increase of transparency is hoped by the information request, regarding the evaluation and exploration of the actives, to be passed as improved. To add, IASB has brought some minor improvements to those measurement and recognizing practices, especially regarding the tests of exploration and evaluation of actives decrease. ${ }^{9}$

In the second stage, the IASB Council approved in April 2004, a research project, which was to be developed by the national accountants from Australia, Canada, Norway and South Africa, a project that was dealing with the accounting for extraction activities, in a general way. The project's team made up a detailed examination of the comments received as an answer to a document called "The Extractive Industries", published by the organism preceding the IASB, the IASC, in November 2000. ${ }^{10}$ The team is accompanied by a consultancy committee, which includes members coming from industry (the sectors of natural gas and oil extraction and mining), accountancy firms, users and organs of the property values settlement from all over the world. ${ }^{11}$

The international financial reporting standard "Exploration for and evaluation of mineral resources" has been validated on the $1^{\text {st }}$ of January 2006. Regarding this aspect, ED 6 was proposing that IFRS should apply annually starting with the $1^{\text {st }}$ of January 2005 . The Council has yet decided to change the validation date with the $1^{\text {st }}$ of January 2006 , so as to offer more time for the entities regarding the transition at IFRS. In the same time, it has decided to permit to one entity, which wants or is demanded to adopt IFRSs before the $1^{\text {st }}$ of January 2006, to adopt IFRS 6 prior to this date.

The purpose of this international standard is that of naming the financial reporting means for the evaluation and exploration of the mineral resources. The exploration and evaluation of the resources means the search for mineral resources, including oil, natural gas and other similar unregenerative resources, after the entity has got legal rights to explore a certain area, as well as determining the technical and commercial reliability of the mineral resources extraction.

The IASB Council objectives for this project phase regarding the extractive activities are the following: [a] proceeding limited improvements of existing accounting practices for evaluation and exploration expenses, without requesting major changes, which could be canceled when the Council will put up a comprehensive review upon the accounting policies used by the entities involved in the exploration and evaluation of the mineral resources; [b] to specify the circumstances

\footnotetext{
${ }^{9}$ Adaptation after International Accounting Standards Board, Press Release: IASB issues Standard on the Exploration for and Evaluation of Mineral Resources, 9 December 2004, the website www.iasplus.com and L. Malciu, N. Feleaga, cit. op., page 193-194.

${ }^{10}$ The International Accounting Standards Board founded in 1998 a Consultancy Board which would do the initial works regarding the accounting and the financial reporting for the entities involved in extractive activities. The result of the activity developed was that of publishing the conclusion paper: the extractive industries.

${ }^{11}$ International Accounting Standards Board, cit. op., International financial reporting standard 6: Basis for conclusions to IFRS 6, BC5, page 624 .
} 
in which the entities who recognize exploration and evaluation actives must test these actives as according to IFRS 6 and evaluate any decrease in accordance with IAS 36 "The Actives Decrease"; [c] to request from the entities involved the presenting of information that identify and explain values from financial situations, coming from the exploration and evaluation of mineral resources and help the users of these situations to understand the values, the moment of their producing and the certainty of the next fluxes from any recognized exploration and evaluation actives.

The present IFRS is applied by the entities to the expenses with the explorations and evaluations that are performed. The evaluation and exploration expenses are those expenses performed by an entity regarding the exploration and evaluation of mineral resources before the technical and commercial reliability of mineral resources extraction is demonstrated.

This international financial reporting standard is not addressed to other accounting aspects by the entities involved in the mineral resources evaluation and exploration activities. As a result, IFRS 6 would not be applied by the entities to the expenses before exploring and evaluating mineral resources, as, for example, the expenses taken before the entity had obtained the legal right to explore a certain area and neither to those expenses resulted after the technical and commercial reliability of some mineral resources extraction could be demonstrated.

The international financial reporting standard "Exploration for and evaluation of mineral resources" allows the entities to elaborate accounting policies for the exploration and evaluation actives without considering the requests of the paragraphs 11 and 12 from IAS 8 "Accounting Policies, Changes in Accounting Estimations and Errors" ${ }^{12}$. So, an entity which adopts IFRS 6 may continue using the accounting policies that had been applied before its adopting. This includes the continuation of the using of evaluation and recognizing practices which are part of those accounting policies. The IASB Council wanted to limit the entities' need to modify accounting policies for the evaluation and exploration actives, accomplishing this thing by: initializing a temporary exception from the hierarchic parts of the IAS 8 that specifies the criteria used by an entity while elaborating an accountancy policy in that case in which a specific IFRS is not applied and limiting the hierarchic exception impact by identifying some expenses that are to be included or excluded from the exploration and evaluation actives, together with the demand for all the exploration and evaluation actives to be evaluated for depreciation.

On the other hand, IFRS 6 requests those entities who recognize evaluation and exploration actives to perform a depreciation test for these actives when facts and contexts indicate that the accounting value could overcome their recoverable value. In the same time, the depreciation as according to IAS 36 is not recognized, but the depreciation is evaluated as according to that standard, once the depreciation is identified. ${ }^{13}$

4. The exploration and evaluation actives: acknowledgement, accounting treatment, changes in the accounting policies, classification, re-classification, depreciation, information display

The exploring and evaluating actives are the exploring and evaluating expenses, recognized as actives, in accordance with the entities accounting policies. Elaborating those accounting policies, an entity that recognizes evaluation and exploration actives will apply according to IFRS 6.6. - paragraph 10 from IAS 8 "Accounting Policies, changes in accounting estimations and errors". It must be in accordance with this. The paragraph we refer to (number 10 from IAS 8) tells us that the lack of a Standard or Interpretation, specifically applied to a transaction,

\footnotetext{
${ }^{12}$ Paragraphs 10-12 from IAS 8 "Accounting policies, changes in accounting estimations and errors" specify a criteria hierarchy which should be used by an entity for elaborating an accounting policy if none of the specific element IFRSs applies.

${ }_{13}$ International Accounting Standards Board, The International financial reporting standard no 6: Main features of the IFRS, IN5, page 613 .
} 
to an event or condition, will lead to the using of its own professional reason by the entity's leaders, so as to elaborate and apply an accounting policy that leads to information which are: relevant for the users' needs to take economical decisions; and also credible, meaning that the financial situations: reflect exactly the financial situation, financial performances and the economical fund of the transactions, with no influences, prudent and complete, regarding all the significant aspects.

IFRS 6 spears an entity from applying paragraphs 11 and 12 of IAS 8 (that specifies the requests sources and advice which the leaders have to consider in elaborating an accounting policy for one element if neither of IFRS doesn't refer in particular to that element) to its accounting policies for the recognition and evaluation of the exploration and evaluation actives. The first mentioned paragraph contains the next sources of which applicability one must take into account in a decreasing order: the requests and interpretations from the Standards and Implementations regarding similar and linked aspects; and the definitions and recognizing criteria, the activesevaluation concepts, debts-evaluation, incomes and expenses in a general Area. The second excepted paragraph speaks about the sources to be taken into consideration: the most recent theories belonging to other settlers that use a general concept area in order to elaborate the accountancy standards, another accountancy literature and the practices accepted by activity branches, as long as these aren't in conflict with the sources mentioned at paragraph 11 from IAS $8 .{ }^{14}$

This international financial reporting standard allows different accounting practices to continue, given the conditions in which a variety of accounting practices are being applied by the entities involved in the exploration and evaluation of mineral resources. The practices differ from the delay of most expenses to the recognition of all these expenses in the profit-loss account the way they were engaged (BC17). The only continuation condition of applying the accounting policies which were being used by the entity when it had applied for the first time the IFRSs requests is for these to be in accordance with the requests from paragraph 10 from IAS 8 (BC23).

The accounting treatment prescribed by the international financial reporting Standard 6 for the evaluation and exploration actives is to evaluate the cost of those. In this regard, each entity has to establish and lead a solid policy, noting the expenses that are recognized as evaluation and exploration actives. Establishing such a policy involves the entity's taking into consideration of the level at which every expense can be associated with the mineral resources discovery. The expenses linked to the next activities can be included in the initial actives evaluation: the exploration rights acquisition; topography studies, geological, geochemical and geophysical; exploration drilling; diggings; and activities linked to the commercial and technical reliability evaluation regarding the mineral resources extraction. These are examples of expenses mentioned in paragraph 9 of IFRS 6 , without considering the list as being exhaustive. There are expenses which shouldn't be recognized as exploration and evaluation actives, as are those linked to the mineral resources. ${ }^{15}$ For these, the general Area and IAS 38 "Un-body settlings" offers advice regarding the recognition of the actives which appear. As well, according to IAS 37 "Provisions, contingent debts and contingent actives", the entities must admit any moving and relocation obligations that are produced as a consequence of

\footnotetext{
${ }^{14}$ Four members of the IASB Council disagreed regarding the IFRS 6. They expressed a disagree, as they would not allow the entities to consider the alternative of continuing the existing accounting treatment for the exploration and evaluation actives and consider that all entities should be asked to apply paragraphs 11 and 12 from the IAS 8 in elaborating an accounting policy for the exploration and evaluation actives. Those four consider that the IAS 8 demands have a certain relevance and applicability when a IFRS lacks the specific demands, as the case of the entities that admit the exploration and evaluation actives, a true fact, because IFRS permits continuing a diversity of evaluation basis for these elements and because the general Area wasn't considered, may lead to an inadequate recognition of the actives. From these members points of view, if an entity cannot fulfill these demands, it shouldn't be allowed to describe its financial situations as being in accordance with the international standards of financial reporting (International Accounting Standards Board, cit. op., The international financial reporting standard no. 6, Bases for conclusions to IFRS 6: Contrary opinions to IFRS 6, DO2, page 638.)

${ }^{15}$ By postponing the complete study upon the accounting of extractive activities, the IASB Council considered that it was not reliable to define now which expenses should be included and which shouldn't in the exploration and evaluation cost.
} 
the involvement of mineral resources evaluation and exploration.

After recognition the entity should apply for its evaluation and exploration actives either the cost-based model or the reevaluation-based one. If the latest model is adopted (using either the IAS 16 model or IAS 38 model), than the reevaluation model must be constant with the actives classification.

According to IFRS 6.13., an entity can modify the accounting policies regarding the exploration and evaluation expenses if this change determines the obtaining of some more relevant financial situations for the users' needs to take economical decisions and do not cause financial issues that are more or less credible, but not less relevant for those needs. In order to judge the relevance and credibility, the entity will consider the IAS 8 criteria. The reason for changing accounting policies by an entity involves the proof that the change improves the equalizing of its financial situations with the IAS 8 criteria, without being necessary for the change to lead to a complete fulfillment of these criteria.

Presenting the exploration and evaluation actives involve their classification by each entity, by grouping in body and non-body actives, by the nature of the gained actives, a classification which must be applied consistently. There are exploration and evaluation actives that are being treated as non-body, as for example, the drilling rights, while some others are seen as body ones (example: vehicles and drilling equipments). If a body active is used to make up a non-body settling, the value reflecting its consume will be part of the non-body setting cost. In spite of all these, using a body active for obtaining a non-body setting does not turn that body active into a non-body settling. ${ }^{16}$ At this moment, prior to ending the complete study on accountancy practices for extractive activities, the IASB Council did not wish to decide if and which exploration and evaluation actives should be classified as being body or non-body, concluding that their nature is the criteria of classification on the two categories, a classification that constitutes the basis for choosing the accountancy policies and for the requested presentations by IFRS 6 .

When the technical and commercial reliability of mineral resource extraction is provable, an exploration and evaluation active will not be classified like this anymore. Before reclassification, the exploration and evaluation actives will be tested for depreciation and any depreciation loss will be recognized.

According to IFRS 6.18., the exploration and evaluation actives must be tested for depreciation when the facts and circumstances suggest that the accounting value of an exploration and evaluation active can overcome its recoverable value. In this way, when the facts and circumstances suggest that the accounting value overcomes the recoverable value, the entity will evaluate, present and describe any loss resulted from depreciation as according to IAS 36, with the exceptions mentioned by IFRS 6.21. IASB has decided that until the entity has enough data to determine the technical and commercial reliability, the exploration and evaluation actives must not be evaluated for depreciation.

The financial reporting standard 6 count (at paragraph 20) the following facts and circumstances that indicate the fact that the entity should test the exploration and evaluation actives for depreciation: [a] the period of time the entity has the right to explore a certain area has expired or will expire in the near future and a renewal is not coming; [b] substantial expenses for the continuing exploration and for mineral resources evaluation in that area are not foreseen in the budget and neither planned; [c] the evaluation and exploration of mineral resources from a certain area hadn't led to the discovery of some commercially reliable mineral resources quantities and the entity decided to end this kind of activities in the area; and [d] there is enough data to indicate that, although a development is possible in the area, is little probable that the accounting value of the evaluation and exploration active to be completely recovered as a result of its selling or put into value. In any of the counted cases, but also in other similar cases, the entity has to make a

\footnotetext{
${ }^{16}$ International Accounting Standards Board, cit. op., The international financial reporting standard no. 6, paragraph 1516 , page 616 .
} 
depreciation test as according to IAS 36, accepting that any depreciation loss to be accepted as expense.

Regarding the specification of the level at which the actives are tested for depreciation (paragraphs 21 and 22), the entity will determine accounting policies for the allocation of exploration and evaluation actives to cash-generating units ${ }^{17}$ or to cash-generating unit-groups with the purpose of testing these actives for depreciation. The cash-generating unit or the cash-unit groups to which an exploration and evaluation active is allocated shouldn't be bigger than a segment of activity, that has as a basis the primary or secondary reporting format, determined according to IAS 14 "Segments reporting". The level identified by the entity to test for depreciation the exploration and evaluation actives may comprise one or more cash-generating units.

Each entity that applies IFRS 6 must present information which can identify and explain the values recognized in its financial situations that appear as a result of the exploration and evaluation of mineral resources. As well, in accordance with the above mentioned, the entity has to present information regarding the accounting policies for the exploration and evaluation expenses, the accounting policies for the recognition of evaluation and exploration actives, but also the active values debts, incomes and expenses, the investment treasury fluxes of those appearing from the exploration and evaluation of the mineral resources. The entity has to deal with the exploration and evaluation actives as if they were a separate class from the other actives, presenting the requested information by the IAS 16 or the IAS 38, by the way in which the actives are classified.

\section{Selective bibliography:}

1. Dutescu Adriana, Guide for understanding and applying the International Accounting Standards, CECCAR Publishing House, Bucharest, 2001;

2. Malciu Liliana, Feleaga Niculae, Reform after reform: the accounting from Romania in front of a new challenge, vol. I, Essays and the standards analysis IAS-IFRS, Economica Publishing House, Bucharest, 2005;

3. The International Accounting Standards Board, The International Financial Reporting Standards including the International Accounting Standards and their Interpretations on the $1^{\text {st }}$ of January 2006, CECCAR Publishing House, Bucharest, 2006;

4. The website www.iasplus.com.

\footnotetext{
${ }^{17}$ The cash-generating for the exploration and evaluation actives represents the smallest identifiable active group, that generates cash fluxes from the continuing using and which are checked, from the depreciation point of view, by an entity, taking into account the accounting policies applied in its most recent annual financial reporting.
} 